\title{
L. Improvements in the aquatinta process, by which pen, pencil, and chalk drawings can be imitated
}

\section{Mr. J. Hassell}

To cite this article: Mr. J. Hassell (1811) L. Improvements in the aquatinta process, by which pen, pencil, and chalk drawings can be imitated, Philosophical Magazine Series 1, 37:156, 297-301, DOI: $10.1080 / 14786441108563285$

To link to this article: http://dx.doi.org/10.1080/14786441108563285

曲 Published online: 18 May 2009.

Submit your article to this journal $\pi$

Џll Article views: 2

Q View related articles $\sqsubset$ 
foetid:-in short, I considered her in a fit state for the operation.

The necessity of extirpation in this case, and in the case of Ibrahim, was acknowledged in a consultation, and the operation was fixed for the next day, when the order arrived for me to repair with the army to Alexandria, and obliged me to abandon both these cases.

L. Improvements in the Aquatinta Process, ly which Pen, Pencil, and Chalk Drawings can le imitated. By $\mathbf{M r}$. J. HAsseld, of Clement's Inn*.

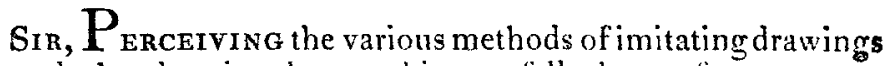
and sketches in the graphic art fall short of an accurate imitation of the black-lead pencil, I determined on an attempt, some years since, which, after repeated experiments, I fiatter myself I have fully established.

The manner is totally new, and solely my own invention:-by the method I adopt any artist can sketch with a black-lead pencil his subject immediately on the copper, and so simple and easy is its style, that an artist can do it with five minutes study.

Bv this manner, the trouble in tracing on oil paper, and other.re-tracing on the etching ground is avoided, and the doubtful handling of an etching-needle is done away, as the pencilling on the copper is visible in the smallest touch :It has also another perfection, that by using a broader instrument it will represent black chalk, a specimen of which I procured Mr. Munn, the landscape-painter, to make a trial of. I have herewith sent the said specimen marked C, and Mr. Munn's name is affixed to the same. This subject he actually drew upon copper, under my inspection, in less than twenty mimutes, the time he would have taken, perhaps, to do the same on paper; in fact, it can be as rapidly executed on copper as on paper.

It is particularly pleasant for colouring up, to imitate drawings, as the lines are soft, and blend in with the colour; It is a circumstance always objectionable in the common method of etching, that those so tinted can never be sufficiently drowned, nor destroyed, and always present a wiry hard effect.

It is equally adapted to historical sketching, and might

* From Transactions of the Suciety for the Encomeragement of Arts, Mumufactures, and Commerce, vol. xxvii. The Society's silver medal and this ty guineas were voted to Mr. Hassell for this communication. 
be the means of inducing many of our eminent painters to hand down to posterity their sketches, which, at present, they decline from the irksome trouble attending the repetition of retracing their performances, and the doubiful handling of the etching-needle, which can never give a sufficient breadth and scope to their abilities.

I have, sir, forwarded, in an annexed paper, the different specimens, for the inspection of the gentlemen forming the Society of Arts, \&c. \&c.

In making my specimens $I$ have thought it necessary to show, if by any accident a part might fail, that it could be re-touched a second time, and oftener if wanted; in this particular its simplicity stamps its use.

To elucidate the foregoing proposition, I purposely caused a part of the distance to fail in specimen AA; this is repaired you will perceive in specimen $B$, and the sharp touches wanted to perfect the sketch are added.

$I$ beg also to state, it is not the style usually termed soft ground etching : that process is always uncertain, cannot be repaired, and will only print about two hundred impressions; whereas the specimens herewith sent will print upwards of five hundred with care.

Should the Society for the Encouragement of Arts, \&c. deem the subject worthy of their reward, I shall feel proud in communicating its process, and flatter myself the arts and artists will feel a peculiar addition and pleasure in its utility. Permit me, sir, to subscribe myself, with all respect,

March 26, 1810.

Your obedient humble servant,
JoHN HASSELL,
Landscape-Draftsman, 11 , Clement's Iun, Strand.

To C. Taylor, M.D. छூc. Eீc. छึc. Process of drawing upon Copper, to imitate Black-lead
Pencil or Chalk.

A remarkable good polish must be put on the copper with an oil-rubber and crocus-martis well ground in oil; after which it must be cleaned off with whiting, and then rubbed with another clean rag.

You are then to pour over your plate the solution to cause ground, which is made as follows :

No. 1.-Three ounces of Burgundy pitch.

One ditio of frankincense.

These are to be dissolved in a quart of the best rectified 
spirits of wine, of the strength to fire gunpowder when the spirits are lighted.

During the course of twenty-four hours this composition must be repeatedly shook, until the whole appears dissolved; then filter it through blotting-paper, and it will be fit to use.

In pouring on this ground, an inclination must be giren to the plate that the superfuous part of the composition may run off at the opposite side; then place a piece of blotting-paper along this extremity, that it may suck up the ground that will drain from the plate, and in the course of a quarter of an hour the spirit will evaporate, and leave a perfect ground that will cover the surface of the copper, hard and dry enough to proceed with.

With an exceeding soft black-lead pencil sketch your design on this ground, and when finished take a pen and draw with the following composition, resembling ink: if you wish your outline to be thin and delicate, caluse the pen you draw with to be made with a sharp point; if you intend to represent chalk-drawing, a very soft nib and broadmade pen will be necessary, or a small reed.

No. 2.-Composition, resembling ink, to draw the design on the copper.

Take about une ounce of treacle or sugar-candy, add to this three burnt corks reduced by the fire to aimost an impalpable powder, then add a small quantity of lamp-black to colour it ; to these put some weak gum-water, (made of gum-arabic,) and grind the whole together on a stone with a muller: keep reducing this ink with gum-water until it flow's with ease from the pen or reed.

To make the ink discharge freely from the pen, it must be scraped rather thin towards the end of the nib, on the back part of the quill, and if the liquid is thick reduce it with hot water.

Having made the drawing on the copper with this composition, you will dry it at the fire until it becomes hard; then varnish the plate all over with turpentine-varnish (No. 3, of the consistency of the liquid varnish sent with this as a sample.

It will now be necessary to let the varnish, that is passed over the plate, drv, which will take three or four hours at Jeast; but this will depend on the state of the weather; for if it should be intensely hot, it ought to be left all night to harden.

Now the varnish is presumed to be sufficiently hard, you may rub off the touche's made with the toregoing described ink with spittle, and use your finger to rub them up; shouid 
it not come off very frecly, put your walling-wax round the margin of your plate, and then pour on the touches some warm water, but care must be taken it is not too hot.

The touches now being clean taken off, wash the plate well and clean from all impurities and sediment of the ink, with cold soft water, then dry the plate at a distance from the fire, or else in the sun, and when dry, pour on your aquafortis, which should be in cold weather as follows:

To one pint of nitrous acid, or strong aquafortis, add two parts, or twice its quantity of soft water.

In hot weather, to one part of nitucus acid add three parts of water.

In every part of this process avoid hard or pump water.

The last process of biting in with aquafortis must be closely attended to, brushing off all the bubbles that arise from the action of the aquafortis on the copper.

In summer time it will take about twenty minutes to get a sufficient colour: in winter perhaps half an hour, or more. All this must depend on the state of the atmosphere and temperature of your room. If any parts require to be stopt out, do the same with turpentine-varnish and lampblack, and with a camel-hair brush pass over those parts you consider of sufficient depth; distances and objects receding from the sight of course ought not to be so deep as your fore-grounds; accordingly you will obliterate them with the foregoing varuish, and then let it dry, when you will apply the aquafortis a second time, and repeat this just as often as you wish to procure different degrees of colour.

Every time you take off the aquafortis the platc must be washed twice with soft water, and then set to dry as before.

To ascertain the depth of your work, you should rub a small part with a piece of rag dipped in turpentine, and then apply the finger, or a piece of rag rubbed on the oilrubber, to the place so cleared, and it will give you some idea of the depth.

The walling-wax is taken off by applying a picce of lighted paper to the back of the plate, all round the opposite parts of the margin where the wax is placed; then let the plate cool, and the whole of the grounds, \&c. will easily come off by washing the plate with oil of turpentine, which must be used by passing a rag backwards and forwards, until the whole dissolves: it is then to be cleaned off by rags; and care must be taken that no part of the turpentine is left banging about the plate.

The plate should only pass once through the press.

Directions 


\section{Directions respecting Grounds.}

No. 1.- The ground in hot weather must have an additional one-third of spirits of wine added to it for coarse grounds, to represent chalk; and one-half added to it for fine grounds, to represent black-lead pencil; and always to be kept in a cold place in summer, and a moderate warm situation in winter.

N. B.-If any parts are not bit strong erough, the same process is to be repeated.

Gum. water must be made in the proportion of half an ounce of gum-arabic to a quarter of a pint of water.

Turpentine-varnish is composed of an ounce of black rosin to an eighth part of a pint of spirits of turpentine : if the weather is excessively warm, it ought to be made with a sixth part of a pint of spirits of turpentine.

Tracing-rag should be made of a piece of Jrish linen, not too much worn, the surface of which is to be rubbed with another rag dipped in sweet vil, just sufficient to retain a small portion of vermilion or pounded red chalk. This must be placed with the coloured part towards the ground of the plate, and the drawing or tracing laid upon it, which must be traced very lightly with a blunt point or needle.

LI. Method of preparing Ox-Gall in a concentrated State for Painters, and for other Uses. By Mr. Richand Cathery, of Mead's Row, Westminster Road*.

I $r$ bas been long a desideratum to find out a method of preparing ox-gall for the use of painters, so as to avoid the disagreeable smell which it contracts by keeping in a liquid state, and at the same time to preserve its useful properties. I have invented a method of doing it with very little expense, which will be to those who use gall a great saving, as it will prevent it from putrefying or breeding maggots.

One gall prepared in my method will serve an artist a long time, as it will keep a great number of years. It will he a convenient aricle for use, as a small cup of it may be placed in the same box which contains other colours, where it will be always ready. The qualities of gall are well known to artists in water-colours, paricularly to those

* From Transactions of the Snciety for the Encourasement of Arts, Masufaciures, and Commerce, vol. xxviti.-...The Society voted ten guineas to Mr. Cathery for this communication. 